\title{
Potential value for new diagnostic markers in the early recognition of acute coronary syndromes
}

\author{
Giuseppe Lippi, MD; Martina Montagnana, MD; Gian Luca Salvagno, MD; Gian Cesare Guidi, MD
}

See also Commentary, page 32.

\begin{abstract}
The diagnostic approach to acute coronary syndromes (ACS) remains one of the most difficult and controversial challenges facing emergency physicians. In recent years, cardiac troponins have emerged as the biochemical "gold standard" for diagnosis of patients with acute chest pain, enhancing our ability to recognize ACS. Early diagnosis and treatment of myocardial ischemia improve patient outcomes, but conventional markers are often nondiagnostic at the time of arrival at the emergency department. Promising new biomarkers, which appear earlier after the onset of ischemia, are being studied and integrated into clinical practice. Some are markers of myocyte necrosis, but others, including ischemia-modified albumin and natriuretic peptides, detect myocardial ischemia and myocardial dysfunction. The aim of the present article is to review the diagnostic approach to ACS, focusing on recent literature describing novel biochemical markers. If ongoing and future studies confirm their role in probability-based models risk assessment, a new era in the diagnostic approach to ACS may be dawning.
\end{abstract}

Key words: acute coronary syndromes; acute myocardial infarction; ischemia modified albumin; laboratory biomarkers; myocardial ischemia; brain natriuretic peptide

\begin{abstract}
RÉSUMÉ
La démarche diagnostique face aux syndromes coronariens aigus (SCA) demeure l'un des défis les plus complexes et controversés auxquels sont confrontés les médecins d'urgence. Au cours des dernières années, les troponines cardiaques sont devenues la «méthode de référence» biochimique pour le diagnostic de la douleur thoracique aiguë, améliorant notre capacité d'identifier le SCA. Le diagnostic précoce et le traitement de l'ischémie myocardique améliorent le pronostic pour le patient, mais les marqueurs conventionnels sont souvent non diagnostiques au moment de l'arrivée du patient au département d'urgence. De nouveaux biomarqueurs prometteurs, qui se manifestent plus tôt après le début de l'ischémie, sont présentement à l'étude et intégrés à la pratique clinique. Certains sont des marqueurs de la nécrose myocytaire, mais d'autres, incluant l'albumine modifée par l'ischémie et les peptides niatrurétiques, détectent l'ischémie myocardique et le dysfonctionnement myocardique. Le présent article a pour but de revoir la démarche diagnostique face au SCA, en se concentrant sur la littérature récente décrivant les nouveaux marqueurs biochimiques. Si les études en cours et futures confirment le rôle de ces derniers quant à l'évaluation des risques à partir de modèles fondés sur la probabilité, une nouvelle ère dans la démarche diagnostique face au SCA pourrait être sur le point de voir le jour.
\end{abstract}

Istituto di Chimica e Microscopia Clinica, Dipartimento di Scienze Morfologico-Biomediche, Università degli Studi di Verona, Verona, Italy

Received: June 3, 2005; final submission: Sept. 23, 2005; accepted: Nov. 13, 2005

This article has been peer reviewed.

Can J Emerg Med 2006;8(1):27-31 


\section{Historical approach to the diagnosis of acute coronary syndromes}

Ischemic heart disease is the number one cause of mortality and morbidity in the Western world, and this unfortunate reality is unlikely to change in the near future. In fact, as advances are made in the prevention and treatment of other severe disorders such as infectious diseases and cancer, the prevalence of acute coronary syndromes (ACS) is expected to increase further. ${ }^{1}$ Despite these facts, the diagnostic approach to ACS remains one of our most difficult and controversial medical challenges. ${ }^{2}$

In 1971, the World Health Organization (WHO) developed a definition of acute myocardial infarction (AMI), which requires the presence of 2 of the following 3 major criteria: chest pain suggestive of myocardial ischemia, ECG abnormalities, and indicative laboratory changes. ${ }^{3}$ The concept of integrating clinical, electrocardiographic and laboratory data was a major innovation, and by the early 1990s the WHO definition had become a cornerstone in clinical and laboratory medicine.

Despite increasing focus on biochemical markers during the last 2 decades, the search for the optimal marker is ongoing. Ideally, a biochemical marker of myocardial ischemia should have the following properties: a considerable concentration in the myocardium; absence from non-myocardial tissue and normal serum; rapid release into the blood at the time of ischemia; a relationship to the extent of injury; and persistence in the blood for a sufficient length of time to provide a diagnostic window. In addition, the test should be rapid, easy to perform and inexpensive. Early markers of AMI, such as aspartate aminotransferase, lactate dehydrogenase and creatine kinase $(\mathrm{CK})$, were non-specific and did not provide definitive proof of myocardial involvement. Assays to measure the enzymatic activity of the CK MB isoenzyme and the derived CK:CK MB ratio were important advances, especially in terms of improved specificity. ${ }^{4}$ The introduction of immunologic mass determination of $\mathrm{CK}$ MB was a major breakthrough that replaced the traditional enzymatic assay. CK MB is not ideal for early risk stratification, but it is the standard against which new biochemical markers are compared with respect to diagnostic accuracy and quantification of myocardial necrosis. Although this innovation did not lead to substantial advances in clinical management, it addressed most of the technical and analytical shortfalls of the earlier CK MB enzymatic activity tests.

Increasing recognition that early diagnosis improves outcomes, ${ }^{5}$ along with concerns about the delayed rise of CK MB after the onset of ischemia, led researchers to study the potential role of myoglobin, a muscle protein that, by virtue of its small molecular size, is rapidly released after myocardial injury. Myoglobin is an early indicator of cardiac ischemia that achieves maximal sensitivity 3 to 4 hours after symptom onset; ${ }^{6}$ however, it is only marginally more sensitive than CK MB early after the onset of symptoms, and it is less sensitive 6 to 8 hours after symptom onset. Because of rapid clearance from the blood, myoglobin may "miss" late-presenting patients, and it is less cardiospecific than CK MB.

\section{The troponins}

By the mid-1990s, advances in the understanding of myocardial injury physiology allowed the identification of structural proteins and intracellular macromolecules that are released when membrane integrity fails. Proteins of the sarcomeric pool, particularly those of the troponin complex, were recognized as potentially effective markers of myocardial injury. On the basis of improved sensitivity and greater tissue-specificity, cardiospecific troponins have evolved into our most important diagnostic markers, becoming the biochemical "gold standard" for patients with acute chest pain, even though, within 24 hours, they appear to have similar diagnostic accuracy to other indicators. An important advantage of the troponins is that their isoforms are unique to cardiac myocytes. In addition, available immunological assays have an analytical sensitivity that allows detection of minimal concentrations of troponins in plasma, enabling identification of much smaller amounts of myocardial injury. Owing to the absolute tissue-specificity, the only limitation that has emerged thus far is the need to discriminate between ischemic and non-ischemic myocardial injury, such as traumatic injury, congestive heart failure, pericarditis and myocarditis. ${ }^{8}$

In 2000, a Joint Committee of the European Society of Cardiology and the American College of Cardiology updated the definition of AMI, identifying troponins as the cardiac markers of choice. ${ }^{9}$ Using these more sensitive markers, many individuals who would previously have been diagnosed with severe, stable or unstable angina pectoris will now be diagnosed as having ACS. However, although the troponins enhanced diagnostic sensitivity, they did not resolve the problem of early diagnosis. In fact, because of slow-release kinetics from damaged myocardium, cardiospecific troponins are often unsuitable for early diagnosis because $40 \%-60 \%$ of ACS patients present with nondiagnostic concentrations. ${ }^{10}$ Markers that rise more rapidly during ischemia would help "rule out" AMI faster and enable earlier treatment of patients with true myocardial in- 
jury. Although CK MB and myoglobin do rise earlier following ischemia, they do not rise before the onset of irreversible damage and they are, especially in the case of myoglobin, less specific for cardiac injury. Other promising markers, such as unbound free fatty acids, free fatty acid binding protein and the glycogen phosphorylase BB, which are slightly more cardiospecific than myoglobin, have not yet been demonstrated to have clinical value..$^{2,11}$

\section{Novel predictors of myocardial ischemia}

Several risk stratification tools have been developed for use in patients with acute chest pain, but none allow clinicians to determine which patients can safely be discharged from the emergency department after a brief assessment. ${ }^{12,13}$ Christenson and colleagues recently reported that the current approach to evaluation and disposition of cases of chest discomfort in Canadian emergency departments misses up to 5.3\% of ACS cases, while consuming considerable health care resources to treat patients who do not have myocardial ischemia; ${ }^{14}$ however, innovative modalities have been recently developed that may improve both the safety and efficiency of the diagnostic approach.

ACS is a complex syndrome with a heterogeneous etiology and a physiologic continuum of events progressing from plaque instability to plaque rupture, intracoronary thrombus, reduced coronary blood flow, myocardial ischemia, reversible damage and necrosis. ${ }^{15-17}$ Most of these events are clinically unrecognizable and biochemically undetectable until the onset of necrosis. In addition, the sensitivity of necrosis markers is time-dependent and even the more highly sensitive and specific markers often give false-negative results on admission. Conversely, novel markers that reflect inflammation or activation of hemostasis following plaque rupture (e.g., myeloperoxidase, soluble CD40 ligand, pregnancy-associated plasma protein-A, interleukin- 6 , serum amyloid $A$, high sensitivity-C reactive protein, D-dimer, prothrombin fragment $1+2$, thrombin-antithrombin complex, soluble fibrin monomers) may be elevated before the onset of irreversible injury. Unfortunately, many of these require cumbersome assay techniques and most lack specificity, precluding their inclusion within probability-based models for assessing individual risk. ${ }^{18,19}$

Ischemia modified albumin (IMA), as measured by the albumin cobalt binding assay, has been recently proposed for early detection of myocardial ischemia without infarction. ${ }^{20-23}$ During ischemia, albumin's capacity to bind with transition metals like cobalt is reduced, probably due to modification of N-terminal metal binding domains on the albumin moiety, especially at the aspartyl-alanyl-histidyl- lysine sequence..$^{24}$ Lippi and colleagues recently speculated that in vivo generation of IMA could be interpreted as an efficient endogenous response to ischemia, preventing myocardial damage or limiting the extent of myocyte necrosis. ${ }^{25}$ In clinical studies, IMA has been shown to rise within minutes after the onset of ischemia, remain elevated for 6 to 12 hours, and return to baseline within 24 hours. ${ }^{26}$ Based on this premise, any IMA increase at the time of admission to an emergency department might be interpreted as an indicator of ischemia before necrosis, displaying up to $90 \%$ negative predictive value at the conventional diagnostic threshold. When results of the IMA assay are added to a traditional panel including myoglobin, $\mathrm{CK} \mathrm{MB}$, and troponins, the diagnostic sensitivity for myocardial ischemia increases from $57 \%$ to as high as $97 \% .{ }^{23}$ Ischemia modified albumin's high negative predictive value (in combination with troponin) means this test could be of value in identifying low-risk patients suitable for early discharge. A non-diagnostic IMA value could perhaps be part of a screening and exclusion strategy for ACS, much like Ddimer measurement is used for ruling out venous thromboembolism. ${ }^{27}$ Conversely, a positive IMA value could identify higher risk individuals who might benefit from early triage and intervention according to stratified pretest probabilities.

Ischemia modified albumin may also be generated in a number of potentially life-threatening conditions that give rise to local or generalized hypoxic circumstances. This means it may be of value in detecting these hypoxic disorders, but gives rise to poor specificity and low positive predictive value for ACS. Of note, increases in serum lactate, especially following vigorous aerobic training, may interfere with IMA testing, but the latter is not a frequent circumstance in patients admitted to an emergency department for evaluation of acute chest discomfort. ${ }^{28}$

Along with IMA, the pregnancy-associated plasma protein-A (PAPP-A), a zinc-binding matrix metalloproteinase expressed in eroded and ruptured atherosclerotic plaques, may serve as a marker of plaque destabilization. The PAPP-A level has been recently acknowledged as a strong independent predictor of cardiovascular events in patients with ACS, and increased plasma levels might help identify patients at higher risk of myocardial ischemia. ${ }^{29,30}$

B-type natriuretic peptide (BNP) is a 32 amino acid protein whose levels are elevated in a majority of patients with acute congestive heart failure. Because BNP and the N-terminal fragment of its prohormone (NT-proBNP) are released from cardiac myocytes in response to increases in ventricular wall stress, they are increasingly used in clinical practice as diagnostic or prognostic biomarkers. ${ }^{31}$ The 
strong association between natriuretic peptides and outcomes in patients with ACS suggests a potential role in early risk stratification for a patients with myocardial ischemia. ${ }^{31-34}$ In a recent prospective study of emergency department patients with chest pain, Bassan and coworkers demonstrated that the combined use of BNP, CK MB and troponin-I on admission (either one abnormal) increased diagnostic sensitivity and negative predictive value relative to CK MB or troponin-I alone. Even in patients with normal levels of troponin-I on admission, a raised BNP value was associated with a significantly greater risk of AMI. Therefore, while BNP is not a specific marker of ACS, it is a strong predictor of ACS, especially in patients with chest pain, no ST-segment elevation, and non-diagnostic concentrations of other traditional biomarkers. ${ }^{33} \mathrm{~B}$-type natriuretic peptide may also be elevated, and is associated with adverse outcomes, in the presence of atrial arrhythmias, pulmonary embolism, renal failure and critical illness with shock. $^{31}$

\section{Conclusions}

Failure to recognize ACS often has unfavourable consequences for patients and physicians. ${ }^{35}$ More efficient diagnostic tools are still needed to help clinicians identify patients with suspected ACS who can safely be discharged from the emergency department after a short and cost-effective investigation. ${ }^{14}$ Whereas traditional cardiac biomarkers depend on myocyte necrosis as a surrogate indicator for myocardial ischemia, IMA may predict the onset of irreversible cardiac damage before irreversible injury, and BNP might provide valuable prognostic information. These modalities could facilitate earlier diagnosis and more appropriate treatment, especially in patients without electrocardiographic findings or elevations of other traditional markers, thus producing cost-effective outcome benefits for patients.

The diagnostic value of IMA and natriuretic peptides is currently under evaluation, and these test modalities may be important components of a future multi-marker diagnostic approach to ACS. If future studies can confirm the added diagnostic value of these potentially promising markers in biochemical rule-out strategies, a new era in the diagnostic approach to ACS could be dawning.

Competing interests: None declared.

\section{References}

1. Lampe FC, Morris RW, Walker M, et al. Trends in rates of different forms of diagnosed coronary heart disease, 1978 to 2000 : prospective, population based study of British men. BMJ 2005; 330:1046.

2. Rosalki SB, Roberts R, Katus HA, et al. Cardiac biomarkers for detection of myocardial infarction: perspectives from fast to present. Clin Chem 2004;50:2205-13.

3. Fox KAA, Birkhead J, Wilcox R, et al. British Cardiac Society Working Group on the definition of myocardial infarction. Heart 2004;90:603-9.

4. Karras DJ, Kane DL. Serum markers in the emergency department diagnosis of acute myocardial infarction. Emerg Med Clin North Am 2001;19:321-37.

5. Ryan TJ, Antman EM, Brooks NH, et al. 1999 update: ACC/AHA guidelines for the management of patients with acute myocardial infarction. A report of the American College of Cardiology/American Heart Association Task Force on Practice Guidelines Committee on Management of Acute Myocardial Infarction. J Am Coll Cardiol 1999;34:890-911.

6. Ohman EM, Casey C, Bengtson JR, et al. Early detection of acute myocardial infarction: additional diagnostic information from serum concentrations of myoglobin in patients without ST elevation. Br Heart J 1990;63:335-8.

7. French JK, White HD. Clinical implications of the new definition of myocardial infarction. Heart 2004;90:99-106.

8. Panteghini M. Role and importance of biochemical markers in clinical cardiology. Eur Heart J 2004;25:1187-96.

9. Myocardial Infarction Redefined - A Consensus Document of the Joint European Society of Cardiology/American College of Cardiology Committee for the Redefinition of Myocardial Infarction. J Am Coll Cardiol 2000;36:959-68.

10. Penttila I, Penttila K, Rantanen T. Laboratory diagnosis of patients with acute chest pain. Clin Chem Lab Med 2000;38:187-97.

11. $\mathrm{Wu} \mathrm{AH}$. Analytical and clinical evaluation of new diagnostic tests for myocardial damage. Clin Chim Acta 1998;272:11-21.

12. Fitchett D, Goodman S, Langer A. New advances in the management of acute coronary syndromes: 1 . Matching treatment to risk. CMAJ 2001;164:1309-16.

13. Singh SM, Alter DA. Is routine early invasive management of non-ST-segment elevation myocardial infarction beneficial in elderly patients? CMAJ 2004;171:1046-7.

14. Christenson J, Innes G, McKnight D, et al. Safety and efficiency of emergency department assessment of chest discomfort. CMAJ 2004;170:1803-7.

15. Fuster V, Badimon L, Badimon JJ, et al. The pathogenesis of coronary artery disease and the acute coronary syndromes (1) [review]. N Engl J Med 1992;326(4):242-50.

16. Fuster V, Badimon L, Badimon JJ, et al. The pathogenesis of coronary artery disease and the acute coronary syndromes (2) [review]. N Engl J Med 1992;326(5):310-8.

17. Perers E, Caidahl K, Herlitz J, et al. Spectrum of acute coronary 
syndromes: history and clinical presentation in relation to sex and age. Cardiology 2004;102:67-76.

18. Galvani M, Ferrini D, Ghezzi F, et al. Cardiac markers and risk stratification: an integrated approach. Clin Chim Acta 2001;311: 9-17.

19. Menown IB, Mathew TP, Gracey HM, et al. Prediction of Recurrent Events by D-Dimer and Inflammatory Markers in Patients with Normal Cardiac Troponin I (PREDICT) Study. Am Heart J 2003;145:986-92.

20. Christenson RH, Duh SH, Sanhai WR, et al. Characteristics of an Albumin Cobalt Binding Test for assessment of acute coronary syndrome patients: a multicenter study. Clin Chem 2001; 47:464-70.

21. Roy D, Quiles J, Aldama G, et al. Ischemia modified albumin for the assessment of patients presenting to the emergency department with acute chest pain but normal or non-diagnostic 12 lead electrocardiograms and negative cardiac troponin $\mathrm{T}$. Int $\mathrm{J}$ Cardiol 2004;97:297-301.

22. Roy D, Quiles J, Sharma R, et al. Ischemia-modified albumin concentrations in patients with peripheral vascular disease and exercise induced skeletal muscle ischemia. Clin Chem 2004;50: 1656-60.

23. Anwaruddin S, Januzzi JL Jr, Baggish AL, et al. Ischemia-modified albumin improves the usefulness of standard cardiac biomarkers for the diagnosis of myocardial ischemia in the emergency department setting. Am J Clin Pathol 2005;123:140-5.

24. Gidenne S, Ceppa F, Fontan E, et al. Analytical performance of the Albumin Cobalt Binding (ACB) test on the Cobas MIRA Plus analyzer. Clin Chem Lab Med 2004;42:455-61.

25. Lippi G, Montagnana M, Guidi GC. Albumin cobalt binding and ischemia modified albumin generation: An endogenous response to ischemia? Int J Cardiol. In press.

26. deFilippi C, Yoon S, Ro A. Early detection of myocardial ischemia by a novel blood based biomarker: the kinetics of ischemia modified albumin. J Am Coll Cardiol 2003;41:6(suppl A):340A.
27. Lippi G, Mengoni A, Manzato F. Plasma D-dimer in the diagnosis of deep vein thrombosis. JAMA 1998;280:1828-9.

28. Zapico-Muniz E, Santalo-Bel M, Merce-Muntanola J, et al. Ischemia-modified albumin during skeletal muscle ischemia. Clin Chem 2004;50:1065.

29. Bayes-Genis A, Conover CA, Overgaard MT, et al. Pregnancyassociated plasma protein A as a marker of acute coronary syndromes. N Engl J Med 2001;345:1022-9.

30. Heeschen C, Dimmeler S, Hamm CW, et al. CAPTURE Study Investigators: Pregnancy-associated plasma protein-A levels in patients with acute coronary syndromes: comparison with markers of systemic inflammation, platelet activation, and myocardial necrosis. J Am Coll Cardiol 2005;45:229-37.

31. Januzzi JL Jr, Camargo CA, Anwaruddin S, et al. The N-terminal Pro-BNP investigation of dyspnea in the emergency department (PRIDE) study. Am J Cardiol 2005;95:948-54.

32. Kragelund C, Gronning B, Kober L, et al. N-terminal pro-Btype natriuretic peptide and long-term mortality in stable coronary heart disease. N Engl J Med 2005;352:666-75.

33. Bassan R, Potsch A, Maisel A, et al. B-type natriuretic peptide: a novel early blood marker of acute myocardial infarction in patients with chest pain and no ST-segment elevation. Eur Heart J 2005;26:234-40.

34. Bettencourt P, Azevedo A, Pimenta J, et al. N-terminalpro-brain natriuretic peptide predicts outcome after hospital discharge in heart failure patients. Circulation 2004;110: 2168-74.

35. Borgundvaag B. Your cheatin' heart [editorial]. Can J Emerg Med 2003;5(2):124-6.

Correspondence to: Prof. Giuseppe Lippi, MD Istituto di Chimica e Microscopia Clinica, Dipartimento di Scienze Morfologico-Biomediche, Università degli Studi di Verona, Ospedale Policlinico G.B. Rossi, Piazzale Scuro, 10, 37134 - Verona, Italy; tel 0093-045-8074516, fax 0039-0458201889, ulippi@tin.it 